\title{
SEQUeSTRO E RESGATE DO CONCEITO DE NECROPOLÍTICA: CONVITE PARA LEITURA DE UM TEXTO ${ }^{1}$
}

\author{
Suze Piza ${ }^{2}$
}

\begin{abstract}
Resumo: Neste ensaio filosófico, discute-se o uso superficial que tem sido feito pela academia, de um modo geral, do conceito de necropolítica do filósofo camaronês Achille Mbembe, bem como da apropriação desse conceito nas redes sociais. Expóem-se as origens filosóficas do conceito e a tradição em que ele está inserido, com indicação de fontes fundamentais para sua construçáo. Com isso, procura-se expor, mesmo que sumariamente, uma definiçáo da necropolítica, ao mesmo tempo que se convoca o leitor ao estudo dos textos necessários para sua compreensão. Buscou-se problematizar, como pano de fundo, uma série de questôes que atravessam hoje a academia, quando adota o pensamento decolonial e as tarefas que se encontram pela frente.
\end{abstract}

Palavras-chave: Necropolítica. Tradição filosófica. Produção de pensamento.

\section{INTRODUÇÃO: AFINAL, DO QUE FALAM OS QUE FALAM DE NECROPOLÍTICA?}

Achille Mbembe, filósofo camaronês, é autor de Crítica da razão negra. Uma daquelas obras que já nascem clássicas, por representar um marco, predestinadas a atravessar os tempos, por sintetizar uma época de maneira singular. Crítica da razão negra foi escrita em 2003, uma década antes, portanto, do Ensaio publicado originalmente na Public Culture, ${ }^{3}$ intitulado Necropolitica

${ }^{1}$ Este texto é resultado de conversas com meu amigo Daniel Omar Perez e do grupo de estudos com meus alunos e colegas da UFABC, realizado no período da quarentena da pandemia da Covid-19, em 2020 .

2 Docente na Universidade Federal do ABC (UFABC), São Paulo, SP - Brasil. (D) https://orcid. org/0000-0002-2394-6072. E-mail: suze.piza@ufabc.edu.br.

${ }^{3} \mathrm{O}$ ensaio Necropolitica foi publicado originalmente em Public Culture, v. 15, n. 1, p. 11-40, 2003, traduzido e publicado na revista brasileira Arte \& Ensaios (revista do PPGAV/EBA/UFRJ) n. 32, dez.

https://doi.org/10.1590/0101-3173.2022.v45esp.08.p129

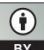

This is an open-access article distributed under the terms of the Creative Commons Attribution License. 
que trago neste texto, para reflexão. Como subtítulo do Ensaio, Mbembe usa conceitos que guiarão toda a sua reflexão: biopoder, soberania, estado de exceçâo e política da morte. Nos últimos anos, o conceito necropolítica tem sido usado cada vez com mais frequência, no Brasil, quando se faz referência a governos ou governantes e suas políticas públicas ou ausência delas e, principalmente, suas formas de governar.

Para os que estão familiarizados com a tradição filosófica mobilizada por Achille Mbembe, bastam esses conceitos usados no subtítulo do Ensaio para identificar rapidamente a linhagem teórica, referências filosóficas principais e, portanto, qual o campo epistemológico ao qual o filósofo pertence: Mbembe vem acompanhado, dentre outros, de Michel Foucault e Giorgio Agamben.

Por outro lado, aos que não têm familiaridade com as referências filosóficas, por não habitar este mundo tâo restrito da academia filosófica, bastará ler o Ensaio, pois, já nas primeiras páginas, há a referência direta a esses autores e também às suas fontes, como Carl Schmitt (pensador nazista de qualidade teórica inquestionável, o qual, ao ser base de teses de Giorgio Agamben, passou a ser citado por outros teóricos sem grandes dilemas morais) ou ainda outro clássico da Filosofia política, a filósofa Hannah Arendt, que não poderia faltar em um Ensaio que visivelmente, mesmo que em perspectiva decolonial, quer fazer parte do jogo teórico ocidental de compreender o que está acontecendo entre nós.

Isso me permite dizer que, mesmo com as fontes europeias explicitadas nas primeiras páginas do Ensaio, para a percepçáo imediata de qualquer um que se aproxime para ler, é importante ressaltar que há uma perspectiva decolonial que molda a maneira da relação de Mbembe com essas filosofias. A Filosofia é um saber territorializado, tem sentido geográfico, e o ponto de vista do filósofo muda significativamente o conteúdo de um pensamento, pois se trata da forma como se usam os recursos epistêmicos para produção de pensamento sobre o mundo. Logo, as fontes citadas no Ensaio náo colocam Mbembe em uma linha de continuidade com esses autores ${ }^{4}$, todavia, indicam, com certeza, uma outra relação com a tradição filosófica: uma relação não subserviente com a Filosofia.

2016) e, em 2018, em formato de livro, pela N-1 Ediçóes.

${ }^{4}$ As principais referências teóricas de Mbembe, para a criação do conceito de necropolítica, foram Hegel, Foucault, Agamben, Bataille, Arendt, Schmitt e Fanon. 
A relação é não subserviente, mas não inexistente. Quando se pensa na criação de um conceito filosófico, mesmo em perspectiva decolonial, há que se pensar como se deu a relação com a tradiçâo europeia, haja vista o predomínio do pensamento europeu entre nós. No caso de Mbembe, a relação existe e é importante, porque certamente esse Ensaio (e o conceito que surgiu dele) não existiriam sem essa tradição.

Apontar para esse fato contribui com a denúncia da situação cada vez mais corrente nos debates acadêmicos nos quais, ao se mencionar o conceito de biopolitica de Foucault, ao lado da necropolitica de Mbembe, aparecem manifestaçôes contrárias à aproximação entre os filósofos. Para alguns, o fato de Mbembe ser um pensador decolonial exigiria imediatamente o rechaço de toda e qualquer filiaçáo europeia. Para outros, a circunstância de Mbembe ser um pensador negro exigiria o rechaço de todo e qualquer pensador branco. Nesse caso, ao se fazer a arqueologia da produção do conceito de necropolítica e sua gênese formal na biopolítica, se contribuiria com racismo epistêmico, pois Foucault e Agamben seriam valorizados, em detrimento de Mbembe.

Esse tipo de postura que tem ocupado o debate público envolvendo o conceito de necropolítica, nos últimos anos, ignora completamente o fato de que o próprio filósofo indica sua filiação filosófica e as bases para a construção de seu conceito. E, como filósofo, aparenta náo ter ressalvas quanto à sua trajetória, formação acadêmica ou fontes, já que as usa muito bem e com bastante tranquilidade para seus fins, inclusive mostrando os limites de seus antecessores. Por se tratar, no caso, de referência a um breve Ensaio, em que essas afirmaçóes que faço são facilmente encontradas, atribuo esse tipo de situaçáo cada vez mais recorrente ao pouco tempo de leitura que as pessoas têm dedicado às suas referências teóricas. Nesse caso, se minha hipótese estiver correta, resta o convite à leitura deste e de outros textos de Mbembe.

Contudo, a relaçáo com esse Ensaio de Mbembe e com o conceito de necropolitica tem sido curiosa também por outros motivos, sobretudo porque, por um lado, alguns entendem que, ao se mencionar a filiação teórica de Mbembe, se desqualifica seu trabalho como filósofo e, por outro, alguns inferem o contrário. Ao verem explicitado o processo de produção de um conceito como o de necropolítica (em que se demonstram a fonte, os limites, a extensão em conceitos como o de biopolítica de Foucault ou de estado de exceção de Hannah Arendt ou Giorgio Agamben), concluem que Mbembe não é filósofo, logo, não teria criado um conceito filosófico. 
Nenhuma das posiçôes se sustenta, haja vista que Achille Mbembe faz o que se faz comumente em filosofia: produz teorias, ao se relacionar com a tradição, dando forma perspicaz e aguda a conceitos em um movimento de negação e conservação. $\mathrm{Na}$ Necropolítica, fica evidente que, apesar de partir de determinadas noções da filosofia política, elas são insuficientes "[...] para dar conta das formas contemporâneas de submissão da vida ao poder da morte." (MBEMBE, 2018, p. 71).

As querelas em torno do conceito de necropolítica remetem a um contexto mais amplo do debate acadêmico, o qual não se restringe ao campo da criação de conceitos e tem causas mais antigas e muito mais profundas. É muito comum, nos círculos acadêmicos, a desqualificação de pensadores do chamado Sul Global - é o assim chamado racismo epistêmico. O racismo, qualquer que seja, incluindo o epistêmico, tem muito que ver com a imagem que se tem de si mesmo: isso não se resolve só com leitura filosófica ou estudo. Talvez, ambas as posturas, tanto a de temer a aproximação com filósofos europeus quanto a de temer a identificação de uma filosofia não europeia como Filosofia, tenham raízes em um passado colonial. Um passado que não passa.

Quando pensamos na recepçấo de um texto ou autor, estamos, portanto, diante de um contexto com diversas camadas objetivas e subjetivas. Afinal, indicar a filiação teórica de um autor, independentemente de qual seja, é possibilitar compreendê-lo no que ele acolhe e recusa. Quão simplista e binário se tornou o nosso mundo, para que que isso seja um problema! A compreensão do sentido da tradição na produção de um pensamento filosófico implica identificar nos filósofos uma habilidade de usar a tradição sem a repetir. Repetir a tradição é comentar o que outro filósofo afirmou, redigir um artigo ou ensaio reafirmando o que, por exemplo, Foucault afirmou sobre a biopolítica, ou mesmo aplicar o conceito de um filósofo a outro contexto. Mbembe não faz isso, e é nisso que reside sua originalidade. A biopolítica pode ser ponto de partida formal, estrutural, para o conceito de necropolitica, todavia, o ponto de vista de Foucault não permitiria ver o que Mbembe viu.

Saindo um pouco do mundo acadêmico, é possível constatar que poucas foram as vezes em que o sequestro de um conceito filosófico foi tão bem-sucedido quanto o que ocorreu com a necropolítica, nos últimos tempos. As redes sociais e seus usuários mais frequentes gostaram desse conceito e se apegaram a ele. Minha intenção, neste texto, não é focar na superficialidade com que o discurso existe nesses "espaços", apesar de entender esse fenômeno como sintoma de uma sociedade doente. Penso que a melhor forma de contribuir 
para o resgate desse conceito seja mostrar sua pertinência e profundidade, indicando como e com quem ele foi construído, mas principalmente o que podemos fazer com ele.

No percurso deste texto, procuro definir o conceito de necropolitica, nos próprios termos postos por Achille Mbembe, ao mesmo tempo que convoco o leitor ao estudo dos textos necessários para sua compreensão e posterior definição que esteja à altura do conceito, o que náo se esgota em um texto desta natureza, nem com minha contribuição. A reconstrução de um conceito filosófico é trabalho coletivo. Tal tarefa não é possível sem indicar minimamente o difícil contexto no qual se produz pensamento decolonial, no Brasil, e alguns desafios enfrentados por quem o adota como referência teórica.

\section{Ele deIXou SUA PEgadA NA PEDRA. ELE MESMO SEgUIU}

Esse provérbio do Zâmbia é epígrafe do Ensaio Necropolítica, de Mbembe. Nossa sensibilidade contemporânea filosófica já tem condiçóes de lidar com provérbios. E, de fato, nesse provérbio, já está o primeiro ponto extremamente importante para pensar a relação que esse filósofo tem com as teorias que o precedem. A biopolítica, a soberania, o estado de exceção são conceitos forjados pelos filósofos que Mbembe estudou e com quem conviveu, teoricamente, mas é sua própria pegada que ele segue, desde o início, porque as teorias são trazidas pelo filósofo com uma finalidade que não coincide com sua mera apresentaçáo. Desse modo, as teorias são meios, não fins em si mesmas.

Apesar de ser a sua pegada, Mbembe sabe que precisou entender esses conceitos para que pudesse forjar o seu. E, se quisermos acompanhá-lo, principalmente em um breve texto, teremos que fazer o mesmo ou corremos o risco de tratar o conceito de necropolitica de forma superficial. Em suma, qual a chance de compreender o conceito de necropolítica, sem mobilizar conceitos centrais e teorias fundantes que sustentam esse conceito? Nenhuma chance. $\mathrm{O}$ que se escuta no debate público, no geral e com raras exceçôes, é uma palavra e não uma categoria filosófica; o que temos escutado não é discurso articulado para leitura precisa da realidade política brasileira, com o uso de um conceito que serve de operador para compreender o que está acontecendo e, sim, como dizia Martin Heidegger: falatório.

Há algum despropósito em trazer Martin Heidegger para um texto sobre Mbembe? Sobre necropolitica? Talvez seja despropositado e desnecessário, 
considerando as tantas outras formas que existem de enunciar determinadas teses, sem referenciar determinados autores. Mas Mbembe pode trazer e traz vários filósofos da tradição. Heidegger é chamado e citado no Ensaio, para apoiar a argumentaçáo sobre o derramamento de sangue do outro, da morte própria e da morte do outro, recurso precioso buscado pelo filósofo camaronês, em uma das principais obras do filósofo alemão, Ser e tempo, a fim de interpretar a morte, o ser-para-a-morte, afinal, é disso que se trata o tempo todo, da morte. $\mathrm{Na}$ referência em particular, da morte do homem-bomba que requer aproximação extrema com o corpo do outro, da morte que não é apenas “[...] a minha própria." (MBEMBE, 2018, p. 64).

$\mathrm{O}$ uso da ontologia não se resume a esse momento do Ensaio, porque Mbembe usa a ontologia não apenas para pensar as estruturas da sociedade em que vive, mas, sobretudo, para definir o modo de ler a política. Elias Canetti, filósofo búlgaro, com sua magnífica obra Massa e poder, é mencionado por Mbembe para a descrição do que é ser um sobrevivente: aquele que é, porque o outro é morto, aquele que só é, porque existem mortos, aquele que vive um momento de poder, ao sobreviver, que vê o horror da morte desaparecer, quando os corpos se acumulam e "ele" sobrevive vitorioso, pois parece que existiu uma luta que o levou a algum ganho. Chamar Canetti, mesmo que rapidamente, no Ensaio, é uma maneira de lembrar que a forma mais baixa do sobreviver é o matar, contudo, há outras formas de sobreviver e outras formas de "fazer morrer" ou "deixar morrer". Essa tese de Canetti é condição de possibilidade para compreender o conceito de necropolítica.

Ler o Ensaio de Mbembe em meio à pandemia da Covid-19 é eticamente desafiador. Com mais de 610.000 mortos, no Brasil, ${ }^{5}$ estamos presenciando um genocídio que é fruto de um conjunto de açóes articuladas e inarticuladas do Estado brasileiro de longa data, e nos tornamos um dos casos mais exemplares de necropolítica. Cada uma das filosofias mobilizadas por Mbembe, como a de Elias Canetti, faz compreender que a categoria de necropolitica exige de nós um esforço teórico para lidar com mesclas de morte, com essas mortes que nos parecem neutras, dos cadáveres nas valas comuns gerados aos montes, nas epidemias, com as relaçóes sociais se diluindo, enquanto lidamos com o processo político de construção de nós mesmos como massas, as massas dos imunes, daqueles que não morreram: nós, os que sobreviveram à pandemia. Nada disso é recente.

\footnotetext{
${ }^{5}$ Dado aproximado do número de mortos em outubro de 2021.
} 
Não só Heidegger, não só Canetti. Sem Hegel e sem Bataille, o campo semântico-filosófico para pensar o conceito de necropolitica sequer existe, haja vista que Mbembe critica uma tradição da filosofia política que defende projetos de autonomia do sujeito e cuja definição de política é a realização de uma coletividade em uma comunidade ou sociedade de comunicação. Para ele, isso não passa de conto de fadas, concepções frágeis que se sustentam em uma somatória de instituições imaginárias, criadas a partir de uma concepção antropológica fantasiosa e ingênua. Para compreender necropolítica, devemos recompor, com Hegel e Bataille, o trabalho que Mbembe fez, ao mudar o registro que permite definir política como o trabalho da morte. Sem entender a política como "[...] instrumentalização generalizada da existência humana e a destruição material de corpos humanos e populaçóes" (MBEMBE, 2018, p. 10-11), sequer se chega perto de compreender a categoria de necropoder.

O que há de mais superficial nos meios que usam esse conceito, sem considerar as fontes necessárias para sua compreensão, é a inserção do conceito de necropolítica na concepção ingênua de sociedade que o próprio Mbembe critica, ou seja, insere-se o conceito em um modelo de sociedade e de política em que ele não cabe, como se ela fosse uma espécie de anomalia eleitoral recente que, se eliminada, nos levaria de volta ao estado de direito das democracias deliberativas.

O ponto principal da minha ponderação crítica não é a ausência de citação de referências teóricas, ao se tratar de um conceito, desnecessárias para sua compreensão, porém, a desconsideração de seu conteúdo e da forma da sua constituição. A falta de conhecimento das bases dessa discussão leva à superficialidade um conceito que é profundo, a falta de conhecimento leva à simplicidade um conceito que é complexo. Sem as condiçóes necessárias para falar de um conceito, ele perde a sua força. E precisamos dele forte, principalmente neste momento em que, associada à necropolítica, o país enfrenta o cinismo como prática discursiva, uma episteme cínica.

A necropolítica é um projeto de subjugação da vida ao poder da morte e, quando pensada em termos de política institucional, ela é estrutura de Estado, não de governos - mesmo que o exercício do poder se efetive por meio de macro ou micropoderes e seus agentes. Apenas essa definição já nos alerta, no caso brasileiro, para quão frágil é a afirmação segundo a qual apenas agora, desde 2019, vivemos em uma necropolitica. 
Hegel contribui com Mbembe com as categorias de vida, morte e do devir sujeito, centradas no conceito bipartido de negatividade, acarretando transformação, trabalho e luta, que opõem concepçôes radicalmente distintas dos filósofos que escreveram as teorias da filosofia política como um romance da soberania dos povos e realização de indivíduos para a construção de uma sociedade cosmopolita. "A política é a morte que vive uma vida humana", afirma Mbembe com Hegel (2018, p. 12). Usa Bataille, o qual desloca a concepção de Hegel das ligaçóes entre soberania, morte e sujeito, para explorar o confronto com a morte, a experimentação do excesso e o vínculo da morte com o erotismo e a sexualidade. Afinal, como entender aquele-que-se-mata em sacrifício sem reduzir o ato a uma causa objetiva política? Como entender quem é o soberano que ultrapassa todos os limites humanos, ao ser de alguma forma detentor da morte, que viola proibiçóes, que vive diariamente o momento do poder, sem pensar na dimensão psíquica daquele que detém o poder de matar. Como entender o impacto que tem essa prática de morte para a maneira como o Estado faz a gestão da vida e da morte das populaçôes? Todas essas formulações são camadas psicopolíticas da necropolítica.

Mbembe parte - e como não poderia partir? - do Estado nazista (um estado assassino, mas também suicidário) e da bagagem teórica acumulada por Hannah Arendt, para descrever facetas do que depois ele chamará de necropolítica. Arendt e Agamben dão um presente teórico à filosofia política, quando denominam o campo de concentração como exemplar do paradigma (em termos kuhnianos) do que é a política. Sem entender minimamente as condições de possibilidade históricas do totalitarismo (exaustivamente discutidas por Arendt), não se compreende a necropolítica, Da mesma forma, é preciso entender como Agamben relacionará o campo de concentração como modelo do campo do político para perceber como Mbembe pensará o papel da colônia e da plantation. Mbembe constrói conceitos análogos, que Arendt e Agamben não poderiam propor. A necropolitica começa a ser compreendida, quando descrevemos o que, como e contra quem o poder é exercido nesses espaços.

A economia interna da formação de uma teoria política mostra que Mbembe está propondo uma nova forma de pensarmos a própria política, na modernidade. Descrever as bases teóricas, mas também seus modelos práticos, essas topografias recalcadas de crueldades, como ressalta Mbembe, possibilita descrever sua lógica e seu modus operandi.

Nas palavras de Mbembe (2018, p. 30): 
No fim, pouco importa que as tecnologias que culminaram no nazismo tenham sua origem na plantation ou na colônia, ou, pelo contrário - a tese foucaultiana -, que nazismo e stalinismo não tenham feito mais do que ampliar uma série de mecanismos que já existiam nas formações sociais e políticas da Europa ocidental (subjugação do corpo, regulamentaçóes médicas, darwinismo social, eugenia, teorias legais sobre hereditariedade, degeneração e raça). Um traço persiste evidente: no pensamento filosófico moderno, assim como na prática e no imaginário político europeu, a colônia representa o lugar em que a soberania consiste fundamentalmente no exercício de um poder à margem da lei (ab legibus solutus) e no qual a "paz" tende a assumir o rosto de uma "guerra sem fim".

Qual a chance de entender a categoria de necropolitica, a qual, como conceito da filosofia política, é territorializada, sem Frantz Fanon? Nenhuma chance. Aliás, para entender o próprio uso que Mbembe fez de Hegel, a leitura de Fanon é imprescindível. Antes de tudo, Mbembe não é um fanoniano, longe disso. Contudo, usa Fanon. Então, paremos também de criar pacotes teóricos de homens e mulheres por terem a mesma cor ou o mesmo gênero ou por se enquadrarem em denominaçóes epistemológicas abrangentes, como costumamos fazer usualmente em Filosofia. Fanon e sua obra Os Condenados da Terra não são essenciais para entender quem é Mbembe ou sua filosofia, mas conhecer esse filósofo e sua obra é atitude incontornável e indispensável, para compreender o que é necropolítica.

Fanon descreve os impactos objetivo-subjetivos da ocupação colonial e suas especificidades. A espacialização do poder, os seus compartimentos, o poder da morte que opera na cidade do colonizado, a cidade que é criada para isso: colônia, distritos. Não há como tratar de necropolítica sem entender profundamente o que é uma vila agachada, uma cidade ajoelhada, uma cidade acuada (FANON, 1968, p. 29). Antes de usar o termo necropolitica, é imperativo ter compreendido como alguém se torna descartável em um dado espaço e qual o tipo de onto-lógica que permite isso. Importante saber, desse modo, de ontologia da colonização, de tipificação de gente, de hierarquização inferiorizante de seres humanos. Fanon demonstra como a ocupaçáo colonial combina o poder disciplinar, a biopolítica e a necropolítica, mesmo que não use esses conceitos diretamente, e antecipa uma série de teses sobre esses conceitos que aparecerão em Foucault e Mbembe.

Mas, de todas as referências teóricas, a filosofia, cuja "caixa de ferramentas" será largamente utilizada, tanto no Ensaio de Mbembe, 
Necropolítica, quanto na Crítica da razão negra, é a filosofia de Michel Foucault. Ao dar a essa filosofia esse estatuto, não corroboro a posição dos que afirmam que Mbembe é um foucaultiano. Biopolítica não é necropolítica: a segunda categoria foi criada pela insuficiência da primeira, mas Mbembe não recusa Foucault, nega-o dialeticamente.

Nesse sentido, aos que querem elogiar, com razão, o filósofo camaronês: Foucault não elaborou a necropolitica, Mbembe a elaborou. Entretanto, não há nenhuma razão, até para entender o próprio processo de produção da Filosofia, em ignorar os usos que Mbembe fez de Foucault e os "acordos" que há entre os dois, bem como as premissas foucaultianas essenciais a Mbembe, como matéria-prima para a construção da categoria de necropolítica. Desnecessário dizer que não se trata de uma variação de linguagem bio para necro, porém, de uma criação filosófica que certamente foi possível por conta de Mbembe ter um recurso epistêmico que Foucault não teve: a perspectiva decolonial e outros requisitos pessoais fundamentais.

O curso ministrado por Michel Foucault em 1976, Em defesa da sociedade, nos oferece alguns operadores importantes para compreender o conceito de biopolítica; isso serve, apenas, para aqueles que ainda náo o fizeram por outros meios. Mesmo entre os filósofos, esse não é o texto mais conhecido de Foucault: então, apresento em linhas gerais algumas das ideias que aparecem em uma de suas aulas de março. O objetivo principal dessa breve apresentação é trazer para a reflexáo certas teses, acompanhadas de seus respectivos conceitos, que podem servir náo para apreender o pensamento de Foucault, atualizá-lo, ou resenhá-lo, mas táo-somente para pensar na diferença, que é o que Mbembe fizera e faz para a construção da necropolítica.

Dentre as teses de Foucault para construir, nesse curso, a noção de biopolitica, destaco as seguintes:

a) Há um deslocamento histórico que ocorre no final do século XVIII, o qual é também um deslocamento dos usos do poder, que abandonará o homem-corpo como alvo principal do poder para eleger o homem-espécie: aí nasce o biopoder, a biopolítica;

b) O campo de aplicação da biopolítica, essa nova forma de poder, é a população;

c) Há uma mudança na forma da governamentalidade do Estado: deixa-se de governar territórios para governar pessoas; 
d) A biopolítica é uma racionalidade de gestão da vida e da morte, como jamais vista anteriormente e com impactos severos até hoje.

$\mathrm{Na}$ aula de 17 de março de 1976, Foucault afirma que um dos fenômenos fundamentais do século XIX foi uma tomada de poder sobre o homem enquanto ser vivo e, com isso, o Estado se apoderou de várias formas do biológico, havendo uma espécie de "estatização do biológico" (FOUCAULT, 2002, p. 286). Foucault resgata, na teoria política, uma teoria clássica da soberania, cujo direito de vida e de morte é um pilar - afinal, é o soberano quem decide quem vive e quem morre. Típica das análises foucaultianas, é na sutileza que estará o que ele aponta como mudança fundamental e que vai causar grande impacto na forma como vamos lidar com a vida e com a morte a partir de então. Destaca Foucault (2002, p. 287):

Em última análise, o direito de matar é que detém efetivamente em si a própria essência desse direito de vida e de morte; é porque o soberano pode matar que ele exerce seu direito sobre a vida [...] Não é o direito de fazer morrer ou de fazer viver. Não é tampouco o direito de deixar viver e deixar morrer.

E segue apontando que uma das mais maciças transformaçóes do direito político do século XIX consistiu em acoplar a essa prática uma maneira muito mais sofisticada e racional de exercer o poder de vida e da morte sobre a espécie que consiste em "fazer viver e deixar morrer". Esse novo direito será avassalador e terá impactos severos.

Ao longo da história recente, essa forma de gestão da vida foi usada para enclausurar os loucos, os pobres, domesticar as mulheres, definir quantidades de filhos, criar hábitos em larga escala, padronizar comportamentos, segregar, exterminar.. O biológico foi politizado, mas o curioso é que não foi politizado para a proteção da vida em larga medida ou de proteção do planeta ou da manutenção de modos de existir. $\mathrm{O}$ discurso pode ser de defesa da vida, mas destrói o meio ambiente e as espécies. É uma defesa da vida nua, como diria Agamben. A biopolítica lida com marcos regulatórios e não civilizatórios. É isso que se tem que ter em mente, quando se começa a tratar desse tema.

Essa forma de poder, que Foucault denominará biopolítica, não se dirige ao corpo do indivíduo e, portanto, não é disciplinar, e, sim, se dirige ao homem como ser vivo, uma espécie que forma uma massa global, afetada 
por processos como o nascimento, a morte, a produção, a doença: é uma biopolítica da espécie humana.

Foucault pergunta: de que se trata essa nova tecnologia do poder? Essa biopolítica que foi se instalando? Que estabeleceu controle da proporção dos nascimentos e das mortes, da taxa de fecundidade, de reprodução de uma população? Precisamos explicitar o momento em que tudo isso se tornou objeto do saber, pois, quando isso ocorre e é atrelado ao poder, é que se cria verdade e esferas de realidade. É nesse momento que as populaçôes se tornam alvos da biopolítica, em um regime de aceitabilidade.

O nascimento da biopolítica é o momento de governar os outros, de governamentalidade das pessoas. Esse é um modelo pastoral centrado no pastor que governa seu rebanho. A prática de governar pessoas consolida a biopolitica com um controle populacional e faz com que a população seja um corpo político único, para qualquer fim. A população aparece, para Foucault, nesse momento histórico.

É curioso pensar no "fazer viver e deixar morrer" típico da biopolítica, pois ela é uma espécie de trama de sentidos que faz com que pensemos condicionados às crenças, regras e valores que se articulam ao biopoder e organizemos nossas vidas de acordo com os mesmos elementos. Se pensarmos no contexto das epidemias, a própria doença passa a ser pensada como um fenômeno da população. É sutil, mas muito significativo, deixarmos de ver a doença como algo que representa a morte que se abate brutalmente sobre a vida de alguém, e, sim, como uma espécie de morte permanente, como algo que corrói perpetuamente, diminui e enfraquece a vida, como um fenômeno serial. Isso só foi possível, pois um corpo político foi criado: a população.

A biopolitica se dirige à população e faz com que a população seja um problema político-biológico; esse sujeito "população" é criado pelo biopoder. Por isso, Foucault defende que houve uma estatização do biológico. Esse campo de racionalidade, o qual é também de linguagem, justifica alguém dizer que a economia não pode parar, por conta de um vírus. Só inserindo a doença como problema político de uma população podemos enunciar algo assim.

Esse campo semântico-histórico-político novo dá origem a uma série de maneiras de exercício do "fazer viver e deixar morrer", pois, na racionalidade biopolítica, você decide quais fenômenos são ou não considerados; muitas vezes, os fenômenos mais aleatórios e imprevisíveis podem ser considerados como reguladores da vida das populaçôes. Sendo regulador e náo civilizador, o 
"fazer viver" é um poder contínuo, científico e, aos poucos, vamos percebendo o quanto a regulação da vida não é exatamente "da vida e da morte", mas da natalidade e da mortalidade, dados que, submetidos à estatística, facilitam muito mais a gestão biopolitica como forma de vida, forma de racionalidade, forma de gestão da morte.

Por fim, um dado importante e estrutural para pensarmos o quadro da biopolítica. Tanto o "fazer viver" quanto o "deixar morrer" têm seus dispositivos, e Foucault, nessa aula, toca em um dos temas mais centrais para se pensar as políticas de gestáo da vida e da morte: o racismo. Os mecanismos de Estado para exercer biopoder exigem um mecanismo que faça a máquina funcionar em sua potência máxima.

Segundo Foucault, foi nesse momento que o racismo se inseriu como mecanismo fundamental do poder, tal como se exerce "[...] nos Estados modernos e que faz com que quase não haja funcionamento moderno do Estado que, em certo momento, em certo limite em certas condições, não passe pelo racismo." (FOUCAULT, 2002, p. 304). Achille Mbembe não será tấo condescendente: não há funcionamento do Estado moderno sem racismo e o que, em Foucault, era uma intuição, no que tange ao vínculo do racismo como dispositivo regulador do Estado moderno, em Mbembe, se tornará tese histórico-filosófica.

Quando Mbembe se pergunta se a noção de biopoder é suficiente para contabilizar as formas contemporâneas em que o político, por meio da guerra, da resistência ou da luta contra o terror, faz do assassinato do inimigo seu objetivo primeiro e absoluto, responde negativamente. A noçáo de biopolítica dá conta de compreender a instrumentalização generalizada da existência humana e a destruição material dos corpos humanos e populaçóes? De compreender os campos de morte instaurados em todos os cantos do planeta como nomos do espaço político? Certamente, náo. Ao afirmar sua insuficiência para compreender essas questóes, isso não significa dizer que a necropolítica substitua a biopolitica, pois elas podem operar juntas, ou uma suceder a outra, em diversas situaçóes. Sem a polidez de Foucault, ao tratar do racismo e pensando desde outro território, Mbembe apresentará a necropolítica, no entanto, como sinônimo de política ou como o trabalho da morte - brutalismo. ${ }^{6}$

A raça, presente na argumentação de Foucault, como um dos elementos que, desde o século XVIII é usado para racionalizar/criar os fenômenos

${ }^{6}$ Título de seu último livro: MBEMBE, Achille. Brutalisme. Paris: La Découverte, 2020. 
biopolíticos, já está na fala de Mbembe como dispositivo regulador do Estado, há tempos, oriunda de outras referências filosóficas e históricas. O racismo, propriamente dito, tem lugar proeminente na necropolítica; certamente não por influência de Foucault. Mbembe define a necropolitica como um projeto político, sem dúvida, de subjugação que se sustenta a partir da imaginação da desumanidade de povos ou grupos. Como enfatiza Foucault, o racismo é uma tecnologia (das mais eficientes) que permite o exercício de um dado tipo de poder, do biopoder, ou, como dirá Mbembe, mais tarde, do necropoder. "O racismo regula a distribuição da morte e torna possível as funçóes assassinas do Estado.” (MBEMBE, 2018, p. 18). Arendt, Foucault, Mbembe, em coro, denunciam que o racismo é meio antinatural da morte e é, ao mesmo tempo, o que faz com que ela seja aceitável.

Racismo, homicídio e suicídio são os fenômenos que, quando articulados, provam a fusão completa da guerra e da política, levando a perceber o outro como uma ameaça, um perigo, “[...] cuja eliminação biofísica reforçaria meu potencial de vida e segurança”, tendo sido identificado por muitos como sendo exclusivo do Estado nazista (MBEMBE, 2018, p. 19-20). Afirma Mbembe (2018, p. 21):

\begin{abstract}
Mecanizada, a execução em série transformou-se em um procedimento puramente técnico, impessoal, silencioso e rápido. Esse processo foi, em parte, facilitado pelos estereótipos racistas e pelo florescimento de um racismo de classe que, ao traduzir os conflitos sociais do mundo industrial em termos racistas, acabou comparando as classes trabalhadoras e o "o povo apátrida" do mundo industrial aos "selvagens" do mundo colonial.
\end{abstract}

$\mathrm{Na}$ verdade, essas conjugações de formas de morte não são específicas do nazismo, mas para toda necropolitica, pois, para cada época e território, determinados modos próprios, como campos para implantação do terror são criadas: sistema de plantation, campos de concentração, apartheid, favelas dominadas pelas milícias. São lugares "para morrer" ou "fazer viver de uma dada maneira”, em que a violência, a opressão e/ou a pobreza são experimentadas com base na raça, no gênero e/ou na classe social, como um estigma de pena de morte. 


\section{A FORMA MAIS BEM-SUCEDIDA DE NECROPODER É A OCUPAÇÁO COLONIAL CONTEMPORÂNEA DA PALESTINA}

O Ensaio Necropolitica, apesar de publicado no Brasil somente em 2016, é um texto escrito há quase 20 anos, lançado pela primeira vez em 2003 e, talvez justamente por isso, faz Mbembe referir-se à Palestina. Essa afirmação que uso aqui como subtítulo: "a forma mais bem-sucedida de necropoder é o caso palestino", é muito importante, principalmente para os que sequestraram o conceito de necropolítica, sem ter lido o texto. Mbembe usa o caso palestino como exemplo da ocupação colonial contemporânea, a qual ilustra melhor o encadeamento dos poderes disciplinar, biopolítico e necropolítico.

A combinaçáo dos três poderes permite que o domínio total aconteça. O poder disciplinar age sobre os corpos, com o intuito de domesticá-los e adestrá-los; o biopoder age sobre as populaçôes, com o intuito de fazer uma gestão da vida e da morte, fazer viver de uma dada maneira, matar ou deixar morrer. A necropolitica é a gestão da morte como projeto de criação de mundo de morte e, portanto, não se restringe a formas de governamentalidade, apesar de poder sê-la. A necropolítica é um conjunto de açóes articuladas ou inarticuladas que subjugam a vida ao poder da morte. A biopolítica pode matar e mata circunstancialmente, mas esse não é seu projeto: ela é modo de governamentalidade que cria o sujeito "população", que é seu alvo, e o extermínio não é necessário, já que implica gestão da vida. A necropolítica é projeto de matar ou deixar morrer ou ainda de fazer viver em mundos de morte. Ela existe para isso, essa é sua estrutura.

Em um trecho do Ensaio, Mbembe, em tom preciso, se refere ao caso palestino:

Sob condições de soberania vertical e ocupação colonial fragmentada, comunidades são separadas segundo uma coordenada vertical. Isso conduz a uma proliferaçáo dos espaços de violência. Os campos de batalha náo estáo localizados exclusivamente na superfície da terra. Assim como o espaço aéreo, o subsolo também é transformado em zona de conflito. Não há continuidade entre a terra e o céu. Até mesmo os limites no espaço aéreo dividem-se entre as camadas inferiores e superiores. Em todo lugar, o simbolismo do topo (quem se encontra no topo) é reiterado. A ocupação dos céus adquire, portanto, uma importância crucial, já que a maior parte do policiamento é feito a partir do ar. Várias outras tecnologias estão mobilizadas para esse efeito: sensores a bordo de veículos aéreos não tripulados (unmanned air vehicles), jatos de reconhecimento aéreo, prevenção usando aviōes com sistema de alerta avançado (Hawkeye 
planes), helicópteros de assalto, um satélite de observação da Terra, técnicas de "hologramatização". Matar incorre em mirar com alta precisão. Tal precisão é combinada com as táticas de sítio medieval adaptada para a expansão da rede em campos de refugiados urbanos. Uma sabotagem orquestrada e sistemática da rede de infraestrutura social e urbana do inimigo complementa a apropriação dos recursos de terra, água e espaço aéreo. Um elemento crítico a essas técnicas de inabilitação do inimigo é fazer terra arrasada (bulldozer): demolir casas e cidades; desenraizar as oliveiras; crivar de tiros tanques de água; bombardear e obstruir comunicaçōes eletrônicas; escavar estradas; destruir transformadores de energia elétrica; arrasar pistas de aeroporto; desabilitar os transmissores de rádio e televisäo; esmagar computadores; saquear simbolos culturais e politico-burocráticos do Proto-Estado Palestino; saquear equipamentos médicos. Em outras palavras, levar a cabo uma "guerra infraestrutural". Enquanto o helicóptero de combate Apache é usado para patrulhar o ar e matar a partir dos céus, o trator blindado Bulldozer (Caterpillar D-9) é usado em terra como arma de guerra $e$ intimidação. Em contraste com a ocupação colonial moderna, essas duas armas estabelecem a superioridade de ferramentas de alta tecnologia do terror tardo-moderno .(MBEMBE, 2018, p. 46-48, grifo nosso).

Apesar de ilustrativo, por conter todos os elementos do necropoder, o caso palestino, no entanto, não é suficiente para dar conta de todas as formas da necropolítica, porque a categoria está enraizada não só nos casos exemplares de criação sistemática de mundos de morte com uso de alta tecnologia, mas também em tecnologias específicas de modos de condução da vida social as quais garantam que genocídios programados ocorram, que suicídios coletivos sejam permitidos. Ou seja, não se trata só de matar sistematicamente, contudo, também de deixar morrer e de fazer viver de determinadas formas em mundos de morte.

Em países de modernidade periférica, como o Brasil, a definição de necropolitica ainda está por ser completada com todas as nossas particularidades. O caso palestino e outros mencionados por Mbembe náo nos ajudam muito nessa tarefa, mas servem de ponto de partida; todavia, outros casos de ocupação colonial que usaram a escravidão como base das relaçôes sociais, sim: afinal, nós nos estruturamos ainda como colônia negreira. Do ponto de vista filosófico, apesar da riqueza da atmosfera criada para a categoria de necropolítica, ela não é suficientemente definida e, certamente, merece ser, talvez mais agora do que quando foi criada, por razóes eminentemente práticas.

Entretanto, não creio que a carência seja de definição conceitual do termo em si, já que a leitura cuidadosa do Ensaio (principalmente se realizada 
com o aporte das referências filosóficas que Mbembe usou) oferece elementos suficientes para uma definição. Apesar da defesa da valorização do repertório filosófico, necessário para que tenhamos uma massa crítica capaz de enfrentar os desafios que se apresentam no país, neste momento, não defendo de forma alguma que devamos passar a vida lendo a história da filosofia, sem ousar pensar. É preciso saber "mergulhar" nas teorias e "subir" à superfície, onde a vida e os problemas estão concretamente: é isso que nos ensinam as epistemologias decoloniais. A necropolítica é um projeto de subjugação de vida ao poder da morte, realizada de maneira articulada ou inarticulada, seja pelo Estado, seja pelo Mercado, seja por quem tenha capacidade de exercer poder em uma dada sociedade; com efeito, o modo da operaçáo desse processo de subjugação é a categoria de raça e, por seu intermédio, o racismo que funciona como um dispositivo regulador. O racismo é um dispositivo que regula a distribuição da morte.

O projeto é constitutivo do campo do político, mas realizado na atividade política cotidiana, que tem, como essência ou estrutura ontológica, a morte e o direito de matar em larga escala; logo, a violência colonial é a forma nunca superada de implantar e exercer esse projeto no cotidiano nas sociedades modernas, mobilizando ora o terror, ora o biopoder, ora a segregação, ora o necropoder, de sorte a operar sempre com uma rede de legitimação simbólica discursiva, a qual faz com o que o projeto seja tão bem-sucedido.

\section{Consideraçótes FinaIs}

O título deste texto é "Sequestro e resgate do conceito de necropolítica". Mesmo que sumariamente eu tenha procurado indicar alguns aspectos que justificam a afirmação de que o conceito de necropolítica foi sequestrado, o foco dado foi o distanciamento que o conceito sofreu, no Brasil, de suas raízes filosóficas. Entretanto, seu resgate não implica uma restauração da posse filosófica de um conceito. Mais produtivo, a meu ver, é descrever em termos filosóficos a necropolítica brasileira - e isso não será possível apenas com Mbembe (muito menos com Hegel ou Foucault), assim como não são Agamben ou C. Schmitt os melhores para nos ajudar a descrever nosso atual estado de exceção ou nosso fascismo brasileiro. A perspectiva decolonial de produção de pensamento filosófico alerta que, como povo periférico, temos um privilégio teórico em relação a esses temas e em relação a esses filósofos. É importante começarmos a usar isso a nosso favor, como recurso epistêmico 
para produção de categorias que nos ajudem a diagnosticar problemas e, posteriormente, intervir na realidade.

A sugestão, ao utilizarmos o conceito de Mbembe, é primeiramente proceder como fazemos com o restante da filosofia: ler o texto e suas fontes - pois o filósofo apresenta um conceito potente, o qual é bem mais do que cabe nos discursos correntes e pode ser ponto de partida para algo maior. Queremos aplicálo ao Brasil? Ao que estamos vivendo agora? Se sim, é momento de pensarmos com profundidade sobre as estruturas de nossa sociedade e não apenas nas nossas formas de governo atuais, ou nos acontecimentos históricos dos últimos anos, pois o que Mbembe propóe é repensarmos a própria política como campo, sugerindo que não a concebamos como romance da soberania repleta de ficçôes. Alguns poucos e poucas intelectuais já estão fazendo isso, mas a tarefa é árdua e representa esforço teórico consistente, para enfrentar o que está por vir. O resgate de um conceito, desse modo, implica saber o que fazer com ele.

Sem nenhum tipo de interesse de defender o eterno estudo dos autores, para podermos pensar ou falar sobre eles, eu me preocupo em náo alimentar o contrário, que é a adesáo irrefletida e sem leitura alguma dos autores que temos usado, para pensar sobre o mundo. Continuo defendendo que não escolhamos nossas referências teóricas pela certidão de nascimento. Pensamento decolonial se constrói com muito estudo, rigor, dedicação e construção coletiva de saberes.

PIZA, S. Kidnapping and rescue of the concept of necropolitics: invitation to read a text. Trans/Form/Açáo, Marília, v. 45, p. 129-148, 2022. Edição Especial.

\begin{abstract}
This essay is about discussing the superficial use that the academy has made, in general, of the concept of necropolitics, from cameroonian philosopher Achile Mbembe and its use in social media. The philosophical origins of this concept are exposed along with the tradition in which it is inserted and the the bibliographic sources necessary for its construction. It seeks to expose, even briefly, a more precise definition of necropolitics, at the same time that I invite the reader to study the texts necessary for its understanding. We try to problematize, as a background, a series of issues that cross the academy today when it adopts decolonial thinking and the tasks that lie ahead.
\end{abstract}

Key-words: Necropolitics. Philosophical tradition. Achille Mbembe. 


\section{REFERÊNCIAS}

FANON, F. Os Condenados da Terra. Rio de Janeiro: Civilização Brasileira, 1968.

FOUCAULT, M. Em defesa da sociedade. São Paulo: Martins Fontes, 2002.

MBEMBE, A. Necropolítica. São Paulo: N-1 Ediçôes, 2018.

Recebido: $15 / 8 / 2020$

Aceito: 23/12/2020 
PIZA, S. 